\title{
Special Issue on the 6th International Multi-Conference on Engineering and Technology Innovation 2017 (IMETI2017)
}

\author{
Wen-Hsiang Hsieh* \\ Department of Automation Engineering, National Formosa University Taiwan, ROC
}

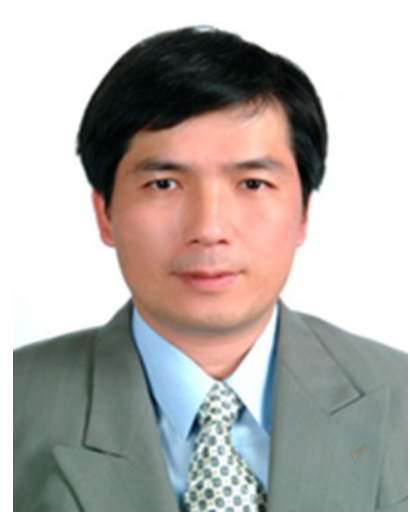

This Special Issue presents 31 papers selected from the proceedings of the 6th International MultiConference on Engineering and Technology Innovation (IMETI 2017) which was held from October 27-31, 2017, in Hualien, Taiwan. The articles in this special issue focus on the newest findings and applications of sensors, including fundamental studies, industrial practices, and engineering innovations by applying sensor technologies. All of the articles underwent a rigorous peer-review. Acceptance into this Special Issue was based on the reviewers' recommendation, mandatory revisions, and final examination by the Guest Editor. It is expected to be an influential issue which could inspire researchers for exploring the technologies of the sensor.

It is my great pleasure to publish the Special Issue in the 30th anniversary of Sensors and Materials. Also, I would like to express my deepest thanks to the reviewers for taking the time to comment on the papers. Moreover, I thank all the authors who have contributed their original work to this issue. Lastly, Special thanks must be delivered to the Editor in Chief/Prof. Makoto Ishida and Ms. Misako Sakano, Editorial Department of MYU K.K., for their kind and proficient supports to the publication of this Special Issue.

Prof. Wen-Hsiang Hsieh Department of Automation Engineering, National Formosa University Taiwan, ROC

${ }^{*}$ Corresponding author. Wen-Hsiang Hsieh, Department of Automation Engineering, National Formosa University Taiwan, ROC. E-mail: allen@nfu.edu.tw. 